Sciendo

\title{
Philosophy as a Protoscience
}

\author{
Cláudio F. Costa \\ Federal University of Rio Grande do Norte
}

Disputatio Vol. 4, No. 34

December 2012

DOI: $10.2478 /$ disp-2012-0022

ISSN: 0873-626X 


\title{
Philosophy as a Protoscience
}

\author{
Cláudio F. Costa \\ Federal University of Rio Grande do Norte \\ BIBLID [0873-626X (2012) 34; pp. 591-608]
}

Where philosophy was, there science shall be.

Robert Nozick

My intention in this paper is to investigate the structural and dynamic relationships between philosophy and science, particularly the view that philosophy anticipates and leads into science. This investigation shades some light on the nature of both, philosophy and science, and on their mutual relations.

\section{The philosophy in its Greek origins as a case study}

When in search of an explanation for the nature of philosophy, a good starting point is to inquire as to its origins. As is commonly known, Occidental philosophy originated in Ancient Greece as a substitute for mythological and religious explanations. Instead of accepting explanations of the foundations and origins of reality based on the anthropomorphic projections of mythology, the early Greek philosophers realized that reality could also be explained speculatively, by appealing to impersonal (or nearly impersonal) principles, for example, water (Thales), air (Anaximenes), the infinite (Anaximander) and being (Parmenides), or living forces like love and hate (Empedocles).... ${ }^{1}$ Questions that could help us to understand the na-

\footnotetext{
${ }^{1}$ In the history of philosophy, equivalents to these principles have continually been proposed: Plato's ideas, Aristotle's substance, Aquinas' God, Kant's thing in itself, Fichte's I, Hegel's absolute, Shopenhauer's will, Heidegger's Being and Wittgenstein's unsayable, played a similar foundational role.
}

Disputatio, Vol. IV, No. 34, December 2012 
ture of philosophy are in this case: What is the reason for this change in explanatory approach? What is the nature of this change?

A good reason for the shift from mythological to philosophical thought has been proposed by historians of philosophy such as W.K.C. Guthrie ${ }^{2}$. According to this author, Greek thinkers, having borrowed scientific knowledge (astronomical, physical, geometrical, arithmetic, etc.) from other cultures, were the first to consider such knowledge in abstraction from practical applications, namely, in the form of theoretical generalizations. We can see the best example of this attitude in Euclid's Elements, with its axiomatic-deductive method of proving theorems. It was this awareness of the explanatory power of theoretical generalization that presumably suggested to early Greek thinkers the possibility that questions once answered by means of the anthropomorphic metaphors of mythology and religion could instead be addressed in terms of abstract speculative generalizations, that is, in philosophical terms.

Although persuasive, this last explanation remains incomplete. Admittedly, the Greeks were the first to consider scientific generalization apart from its application. They were the first to axiomatize geometry, and they were able to produce physical and astronomical generalizations (such as, respectively, the measurement of specific gravity by Archimedes and the heliocentric hypothesis of Aristarchus). However, in order to explain the emergence of philosophical thought it is not enough to consider the emergence of explicit generalizations independently of their practical applications, for this is not a privilege of scientific explanation. Commonsensical explanation, for example, is also based on empirical generalizations, like those conveyed by sentences such as 'The sun always rises', 'Water quenches the thirst', 'Fire burns', etc., which are not scientific but have always been accepted as conveying obvious truths. Moreover, people were certainly always able to consider such trivial generalizations apart from practical concerns.

A more complete explanation for the emergence of philosophy in Greece seems to me the following. When they succeed in creating abstract scientific knowledge, Greek thinkers also achieved an intuitive understanding of the nature of the generalizations and ex-

${ }^{2}$ See Guthrie, W.K.C., A History of Greek Philosophy, vol. 1, p. 36 ff. 
planations of science, as much for the formal sciences (geometric theorems) as for the empirical ones (physical and astronomical laws). Though at the very beginning they didn't have a philosophy of science (the first steps in this direction were taken later by Aristotle in his Organon), they certainly had an idea of the kind of hypothetical, predictive and explanatory procedures that are common to science in general - empirical as much as formal - what we could call an idea of science. Now, it seems that Greek philosophy was born from the speculative application of this idea of science to questions earlier approached exclusively by means of religion, like the question of the ultimate nature of the world and of our place in it. Provided with this new notional attitude, the first Greek philosophers attempted to proceed rationally, first by seeking to establish true generalizations based on some kinds of data (empirical or formal), and then by trying to explain some kinds of facts, whatever their nature, using these generalizations ${ }^{3}$. The first Greek philosophers pursued this aim by introducing vague principles (like water, air, infinitude, being) or forces (like heat and cold, love and hate), which might be interpreted as a first attempt to replace explanation relying on the actions and intentions of divinities with explanation based on the constitutive elements of reality and the impersonal laws regulating their transformations, often hovering midway between the two kinds of explanation. ${ }^{4}$ It is not without reason that Thales, the first philosopher of the Occidental tradition, was also a scientist and a competent astronomer, who once accurately predicted a solar eclipse.

${ }^{3}$ A similar procedure applies even to philosophy understood as conceptual analysis: philosophers usually consider certain data, as they appear in examples, paradigmatic cases, thought-experiments, etc. in an effort to reach some kind of conceptual generalization, by means of which they attempt to explain a large set of conceptual applications.

${ }^{4}$ This phenomenon was already noted by Auguste Comte as he considered the passage from mythological to metaphysical thought. For a discussion, see C.F. Costa: The Philosophical Inquiry: Towards a Global Account, chap. 4. 


\section{Philosophy as a conjectural inquiry lacking consensual foundations}

Assuming that Occidental philosophy arose from the speculative application of the idea of science to questions inherited from mythology and religion, how should we distinguish the activities of philosophers from those of scientists? - for, though there are some suggestions to the contrary, ${ }^{5}$ there seems to be a considerable difference! The answer to this question brings us to what I regard as a central insight into the nature of philosophy. Even if philosophical activity resembles the general procedure of scientific inquiry, there is a fundamental difference in that philosophical explanation remains merely conjectural and, to this extent, speculative. ${ }^{6}$

But what do the words 'conjectural' and 'speculative' mean when we say that philosophical investigation remains conjectural or speculative? One answer is that an investigation is conjectural when it achieves only hypothetical results, and that this is the case when there is no possibility of consensual agreement about the truth of their results. Indeed, while in the sciences it is fairly easy to obtain consensual agreement on results, this kind of consensus is impossible in the muddy waters of philosophical inquiry. Consider the difference: The explanation of how levers work using the laws of levers, as conceived by the Greek scientist Archimedes, was one that everyone could verify practically and agree to. In contrast, the explanation of the generation and destruction of things through the action of the living forces

${ }^{5}$ See, for example, W.v.O. Quine: 'A Letter to Mr. Osterman'. Quine suggests that the boundaries between philosophy and science are arbitrary, like the boundaries between different districts on a map. But if this were true, agreement about new achievements as belonging to philosophy or to science would need to be conventionally settled; however, this is not the case. Such agreements seem to us natural and immediate.

${ }^{6}$ Ludwig Wittgenstein defended the view that philosophy is not constituted by argumentative theoretical conjectures, but is a therapeutic activity of describing how language really works (L. Wittgenstein: Philosophische Untersuchungen, sec. 109). Nevertheless, as many have remarked, neither Wittgenstein nor his followers have come remotely close to achieving this aim; the obscurity and elusiveness of Wittgenstein's arguments don't turn them into descriptions (see, for example, A.J. Ayer: Wittgenstein, p. 137). 
of love (philía) and hate (neíkos) on the four elements (water, air, earth and fire), as the pre-Socratic philosopher Empedocles proposed, was an inevitably vague and obscure speculative dream. It was developed in a way and in a domain of inquiry in which researchers were not able to find a path to consensual agreement.

The conjectural character of philosophical thought - as the result of a lack of consensual agreement on fundamental matters - reveals itself as a necessary property, which is able to explain its typically argumentative and aporetic character. For when thinking cannot be other than conjectural, there is no alternative except to embark on hypothetical reasoning: We begin by accepting certain non-consensual assumptions and then apply our best knowledge and skills to discover all the implications of this acceptance. Then we (usually other philosophers do this) vary the assumptions and proceed in a similar way. And then we try to compare critically the different results and the procedures that lead to them, in a process that can be repeated again and again. In this way, philosophers are always beginning: they are always pondering new ideas in ways that usually generate aporetic argumentative discussion.

Moreover, in the conjectural character of philosophical inquiry we also find an explanation for the lack of progress in philosophy: since philosophers cannot achieve agreement on the truth of their ideas, inter-theoretical comparisons must remain inconclusive. (To give some examples: scientists would generally agree that Einstein's relativistic mechanics is superior to Newtonian mechanics, since the explanatory power of the former is greater - this is a matter of scientific conclusions. On the other hand, philosophers remain divided when the question is, e.g. whether the nominalism of the British empiricists might give a more suitable explanation for the problem of generality and predication than does some sort of Platonic-Aristotelian realism, for this is a matter of philosophical doctrine.)

Still, why can't we achieve consensual agreement about the results of the philosophical work? The answer is that consensual agreement about the results of an investigation is only possible when there is sufficient agreement about the main presuppositions underlying the investigation. A previous agreement about these things is always absent from philosophical inquiry. Philosophy lacks: 
(i) agreement about the adequacy of its data, principles and the questions based on them (philosophical 'data' and principles are uncertain and many philosophical questions, we suspect, are pseudo-problems resulting from linguistic-conceptual confusions);

and philosophy also lacks

(ii) agreement about the adequacy of its methodological procedures for evaluating the truth of answers proposed to philosophical questions (an argument or a set of arguments can appear conclusive to one philosopher and irrelevant to another).

In opposition to this, conditions (i) and (ii) are always sufficiently satisfied in cases of scientific endeavours. For in science the questions and problems are uncontroversial, and the correct solutions, when finally found, can be clearly identified. Indeed, where fundamental conditions like these cannot be met, there is no way to achieve consensual agreement, and we remain doomed to the aporetic discussions typical of philosophy.

\section{Philosophy as a protoscience}

The foregoing remarks suggest that by investigating the similarities and contrasts between philosophy and science we may achieve a better explanation of some central features of philosophical inquiry. Moreover, it invites us to ask if our present philosophical inquiries will someday yield to science, by achieving a degree of maturity that allows its practitioners to reach consensual conclusions. In other words: could philosophy be seen as a conjectural inquiry anticipating science - as a protoscience? Could all philosophical inquiry be seen in this way?

A positive answer to this question is suggested by the historical fact that every new science was born in the cradle of philosophy. Consider some few examples from several scientific fields:

1. According to Karl Popper, the now obvious astronomical consideration that the earth is a body moving in empty space, 
impelled by inertial and gravitational forces, was already anticipated by Anaximander, who suggested that the earth was a stationary cylinder, suspended in the void because it is equally distant from all things, it being impossible for it to move simultaneously in opposite directions ${ }^{7}$.

2. The scientific investigation of subatomic particles by contemporary physics had as forerunner the speculative hypothesis of atomistic philosophers, from Democritus to Epicurus, that visible things are formed by the aggregation of invisible (because extremely small) and physically indivisible particles.

3. Biological theories of evolution seem to be dimly anticipated by Anaximander's insight that since man is helpless as a child, he would have perished in primeval times if he had not developed from more primitive animals...

4. The Platonic theory of the tripartite soul has a modern equivalent in Freud's structural theory of mind, which divides the mind into the ego, the id and the superego, although psychoanalysis still strongly resembles philosophy, insofar as its practitioners remain unable to reach consensual agreement.

5. Wittgenstein's therapeutic view of language as a nebula of language games working as unities of meaning anticipated the more scientific theory of speech acts of J.L. Austin and J.R. Searle, which nowadays belongs more to linguistics than to philosophy.

These are only a few examples. The process is going on in the present days. Many believe, for example, that as soon as we really understand how the brain works, most of the riddles of our present philosophy of mind will yield to consensual (and in this sense scientific) solutions. All these facts lead us to ask whether science might not someday replace the remaining central philosophical fields, such as epistemology, metaphysics and ethics.

Nevertheless, there are philosophers who resist the view of philosophy as a protoscience. Echoing Wittgenstein, Anthony Kenny holds that philosophy, unlike science, deals with knowledge as a

\footnotetext{
${ }^{7}$ This remark is made by K. R. Popper in 'Back to the Pre-Socratics', in his Conjectures and Refutations, p. 138.
} 
whole, since it aims to organize the already known, providing an overview of our knowledge. This kind of comprehensiveness, he argues, is lacking in the individual sciences; central areas like metaphysics, epistemology, the theory of meaning and ethics, at least, will remain forever philosophical ${ }^{8}$.

Nonetheless, an overview and comprehensiveness can be achieved by scientific inquiries too. Therefore, I suspect that the main reason for this resistance lies less in the nature of things than in outdated views of the nature of science still uncritically accepted by many philosophers. For these views, which have their roots in the philosophy of natural science developed by the positivists (and also in the main reactions against them), are often too restrictive to assure our central philosophical interests a deserved place in future scientific inquiry. Consider, for example, Popper's view of science as an inquiry that aims to create theories able to resist falsification by decisive experiments. ${ }^{9}$ This view is too restrictive, even in the 'hard' domains of natural science: it excludes the theory of biological evolution from the domain of science, because it is not decisively falsifiable. How would we conceive an experiment capable of falsifying a hypothesis about a process that occurred in the past? Since we have this problem, how could such a restrictive standard as falsifiability (which may arguably only be applicable in certain fields of physics) ever be applied to the central subject matters of philosophical inquiry, like those of epistemology, metaphysics and ethics, other than in a crassly reductive or even eliminative way?

Indeed, were views like that the only available attempt to identify philosophy with a protoscience, our questioning could stop here. The reason for this is that from the investigation of a well-established particular science we are led almost perforce to restrictive generalizations about the character of still unknown areas of science. What we are looking for is a concept of science so general and inclusive that any new science that should chance to emerge can satisfy it, since this would be precisely the concept of science that we could properly contrast with that of philosophy.

\footnotetext{
${ }^{8}$ Antony Kenny: Aquinas on Mind, p. 9.

${ }^{9}$ See K.R. Popper, Conjectures and Refutations, ibid. pp. 339-340.
} 


\section{The right contrasting view of science}

To arrive at this more balanced view of science we must follow the contrasting direction initially proposed and begin with questions like: what does the scientific community as a whole understand under the word 'science'? How would scientists recognize any new theory or field of investigation as belonging to science? I find such a balanced view of science in the work of John Ziman, who regarded science in general as 'consensualizable public knowledge', that is, as any kind of knowledge susceptible to consensual agreement concerning its results. ${ }^{10}$ According to this view, science is constituted by generalizations consensually accepted as true by the members of a community of ideas. As Ziman shows, this notion has the advantage of being commonsensical: it is in perfect accord with what informed laymen and scientists understand as science. When we talk about science, we are thinking of new knowledge that the community of specialists can surely and precisely evaluate. This view of science is also sufficiently general and flexible to include everything we usually accept or could accept as belonging to the sciences, both the empirical and the formal. Moreover, placing the concept of consensual agreement at the center, Ziman's view of science seems to provide the perfect contrast between philosophy and science, since, as we have seen, the latter is an inquiry identifiable by a lack of consensual agreement concerning its results. Accordingly, even if philosophy might be a comprehensive inquiry aiming to achieve an overview, as Kenny thought, it might also be protoscientific, insofar as the possibility of becoming a sort of consensualizable public knowledge is not excluded in advance.

However, isn't the definition of science as 'consensualizable public knowledge' too inclusive? It seems to be so because there are political, religious and other communities in which a 'consensus' is imposed from above, excluding the possibility of critical evaluation. A notorious example of this is the role played by political ideologies in defining legitimate science in Nazi Germany and the Soviet Union. Yet, following the above characterization, such ideological impositions do

${ }^{10}$ This is the general thesis on the nature of science defended by J. M. Ziman in Public Knowledge: An Essay Concerning the Social Dimension of Science, chapter 2. For current serious discussion of the social dimensions of science, see J. M. Ziman, Real Science; see also H. L. Longino: The Fate of Knowledge. 
seem to pertain to science, since a community of ideas consensually accept them. Thus, Ziman's characterization of science seems unable to distinguish science from a by-product of ideology.

Nonetheless, we see that this difficulty is only apparent, when we distinguish between authentic and inauthentic consensus, specifying what we understand as a community of ideas able to produce science in a way that excludes inauthentic consensus. Keeping the contrast with philosophy in mind, I suggest we call a community able to warrant authentic consensus a critical community of ideas, understanding it as a community which satisfies constitutive conditions approximating those specified by Jürgen Habermas for what he calls an ideal speech situation (ideale Sprachsituation) ${ }^{11}$. This means that we must define a critical community of ideas as something that satisfies constitutive conditions warranting authentic consensus. Without trying to be either systematic or exhaustive, I propose that we can generally characterize the main constitutive conditions for a critical community of ideas as requiring:

(a) Truth-seeking commitment: the members of the community should try to find the truth along the whole process of inquiry and evaluation of ideas.

(b) Freedom of discussion: there must be an equitable potential for free critical discussion among members of the critical community of ideas; they should not be subject to any intellectual constraints, except those of the best arguments.

(c) Full access to information: all members of the community must have full access to information and equal chances for the evaluation and exchange of ideas.

(d) Shared competence: all members must have suitable training in order to be able to make adequate evaluations.

Only the minimal satisfaction of constitutive conditions like these, assuring the freedom and the rationality of the evaluation of the results of the investigation, can produce a truly scientific consensus.

"1 See Jürgen Habermas: 'Wahrheitstheorien' in Vorstudien und Ergänzungen zur Theorie des Kommunikativen Handelns, p. 174 ff. See also H.L. Longino, ibid., p. $128 \mathrm{ff}$. 
In fact, when we evaluate reports of a new scientific discovery, we always do so on the assumption that the scientific community has satisfied the conditions of truth-seeking commitment, free discussion, full access to information, and shared competence, if not ideally, at least to a sufficient degree.

Another important objection that could be opposed to such a consensualist view of science is that it would compromise its objectivity. It seems at first glance that whatever the scientific community decides to call science will be science, arbitrarily disregarding objective criteria. However, this is not how things really are. For the critical community of ideas aims at a consensus about truth, and it cannot achieve this without sharing appropriated objectivity-conditions for the considered epistemic domain. In other words: it turns out to be an unavoidable fact of experience concerning the working of any community of ideas that consensus about truth is only attainable after the fulfilment of appropriate conditions for objective consensus. Therefore, without attempting to be neither systematic nor exhaustive, we can make a list of conditions that altogether must be satisfied by any object of evaluation by a critical community of ideas in order to warrant claiming the presence of the consensual objectivity necessary for the achievement of consensus about truth. This list requires that for the achievement of consensus about truth there must be at least previous agreement about:

(f) what can be counted as the (empirical or formal) elementary data, constituting the epistemic domains to which scientific theories are applied;

(g) what can be accepted as adequately formulated questions to be asked concerning the epistemic domain (theories must answer meaningful questions);

(h) what can be accepted as an adequately constructed theory relative to the epistemic domain (in its internal as well as in its external coherence within a wider conceptual framework); and

(i) what are accepted as the procedures of truth-evaluation relative to the epistemic domain of a theory (which involves some kind of correspondence between a theory and the facts the theory should explain, some kind of verification procedure for the achievement of this correspondence, etc). 
The satisfaction of conditions like these is necessary for the objectivity of the scientific endeavour, coinciding in many ways with the kinds of things that philosophers of science often investigate in a detailed way. The difference is that although these philosophers have often regarded only such conditions, ignoring the social role of the critical community of ideas, we consider these conditions subsidiary to the appropriated functioning of a critical community of ideas. It is not an a priori matter, but an unavoidable matter of fact, seen by any critical community of ideas, that the members of will only achieve consensus about what is true insofar as these conditions are satisfied.

With the aid of these notions, we can improve Ziman's general characterization of science as 'consensualizable public knowledge'. Here is my proposal:

THE SCIENCE $=$ a body of non-trivial generalizations obtained by the members of a critical community of ideas, these generalizations being consensually held to be true by this community.

This seems to be a better view of science, regardless of what some philosophers might think. It is better because it fits well enough with what all people, from scientists to educated laypersons, understand by science in general. To apply the concept of science to any inquiry, our first requirement is the achievement of agreement about the truth of non-trivial generalizations among the members of a critical community of scientists. Only with this in hand can scientific progress take place.

\section{The right contrasting view of philosophy}

The above outlined consensualist-but-objectivist view of science allows us to establish an adequate contrast with philosophy, for now we can characterize the conjectural inquiry of philosophy by similarity and contrast with scientific investigation, as follows:

THE PHILOSOPHY $=$ a conjectural body of investigations aiming at the achievement of true generalizations by the members of a critical community of ideas (the community of philosophers), without this community being able to achieve any consensual 
agreement on the truth of these generalizations.

Following this characterization, any conjectural inquiry in any domain of thought in which it is impossible to achieve a consensual body of truths can be regarded as of a philosophical nature. Its philosophical nature derives from the lack of satisfaction of the conditions (f)-(i) warranting consensual objectivity in a critical community of ideas. Indeed, in those difficult domains where science, understood as 'consensualizable public knowledge', remains impossible, only the conjectural inquiry of philosophy remains available. In this way, we can explain why philosophy, in conformity to the etymology of the word, is the love (phylo) of knowledge and wisdom (sophia) and not its attainment. In the words of Bertrand Russell: 'Science is what we know; philosophy is what we don't know'... 'Science is what we can prove to be true; philosophy is what we can't prove to be false'. ${ }^{12}$ Indeed, when philosophy achieves consensual truth, it ceases to be philosophy and becomes science. Even the metaphilosophical view I am sketching in this paper can yield to science if the critical community of ideas achieves agreement on its truth.

Another point we should note is that the practice of philosophy always presupposes a critical community of ideas, even if in some cases (like those of Vico, Peirce and Nietzsche) in a contrafactual manner. A well-known charge against medieval philosophy is that by accepting Christian dogmatism as above criticism it fell short of satisfying this condition.

Finally, it could be objected that as a typically 'higher-order' form of inquiry, philosophical inquiry is by its own nature incapable of objective verification and, consequently, of the kind of objectively grounded consensus achieved by science. My response is that this view may well be overly pessimistic. The main reason to think so is that support for a theory is not only directly empirical - through verification - but also inter-theoretical. This kind of support can also be found in the sciences. Take, for example, the Darwinian theory of evolution. Darwin and his contemporaries developed this theory without recourse to genetics, since Mendel's work was unknown to early evolutionary theorists. Nevertheless, the subsequent rediscov-

\footnotetext{
${ }^{12}$ Quotes taken from Allan Wood's postscript to Bertrand Russell's My Philosophical Development.
} 
ery of genetic theory by the scientific community provided extremely important inter-theoretical support for evolutionary theory. Something similar can also occur within 'higher-order' philosophical inquiry. In an exaggerated way it has already been suggested that the problems of philosophy are so intertwined that any problem will be only solved when all others have already been solved (Wittgenstein). Far from being pessimistic, this remark points to inter-theoretic support. Insofar as related fields of knowledge approach science, new inter-theoretical support for philosophical insights will be provided, paving the way for consensual scientific knowledge.

\section{Protoscientific versus analytic-conceptual view}

Once we accept the suggested views, we see that the supposedly essential differences in subject matter or even in method between philosophy and science are illusory. Take, for example, the still widely accepted view of the nature of philosophy which holds that it is a non-empirical, higher-order activity of conceptual analysis (its method), intended to make explicit the structure of our most central concepts and the relations holding between them (its subject matter) ${ }^{13}$. This view arose due to the prominence of the philosophy of language in the first half of the Twentieth Century. But it was factually refuted when the philosophy of language, as the most productive philosophical field, was superseded by the philosophy of mind in the second half of the Twentieth Century, since the latter philosophical field consists largely of empirical speculation. Moreover, the fact that a given philosophical inquiry has a linguistic-conceptual character does not mean it cannot develop into a science. This is exemplified by J. L. Austin's theory of illocutionary forces. As he himself foresaw, this theory belongs today, in the form of the theory of speech acts, more to the scientific field of pragmatics than to philosophy. And the reason for this is that it has achieved enough consensual agreement to lose its plastic role

\footnotetext{
${ }^{13}$ The persistence of this view can be exemplified in the essays of Robert Brandom, Barry Stroud, Allen Wood and Karl-Otto Apel, recently published by C.P. Ragland \& S. Reidt in What is Philosophy? For standard presentations of the view see Michael Dummett: 'Can Analytical Philosophy be Systematic and Ought it to Be?' and Ernst Tugendhat 'Überlegungen über die Methode der Philosophie aus Analytischer Sicht'.
} 
in the domain of conjectural thought. Hence, there seems to be no contradiction between the view of philosophy as a protoscience and the view of philosophy as conceptual analysis, since the latter can be regarded as belonging to the former ${ }^{14}$.

Finally, we can offer a metaphilosophical refutation of the thesis that the proper object of philosophy is conceptual. As W. v. O. Quine saw, philosophers often need the resource of what he called a semantic accent. ${ }^{15} \mathrm{~A}$ semantic accent is what we could also call a semantic metalanguage. A semantic metalanguage is something different from a syntactic metalanguage: while the latter has as its objects signs and their relationships, the former has as its objects as well the meanings and with them, indirectly, the world as we mean it. (For example, instead of saying, 'Five is not a thing but a number', one would say, 'Five' is not a thing-word, but a number-word'). This need not lead us astray, for it is nothing more than a propaedeutic resource aiming at the achievement of the kind of conceptual transparency usually demanded by philosophical arguments. Even when philosophers like Rudolph Carnap have seen here a proof that the object of philosophy should be purely linguistic-conceptual, this cannot be true, as Quine also noted, because every sentence of the empirical sciences can also be metalinguistically represented in this way. As he noted:

There are wombats in Tasmania' might be paraphrased as "Wombats' is true to some creatures of Tasmania' if there were any point in it; but it does happen that semantic accent is more useful in philosophical connections.

The upshot of this is that philosophy does not have concepts (like those of meaning or knowledge or consciousness or substance) as its proper subject matter, any more than science (with concepts like those of genes, molecules and superstrings), and no more than any-

${ }^{14} \mathrm{~J}$.L. Austin also saw no contradiction between philosophy as protoscience and philosophical analysis, since on the one hand he championed philosophy as conceptual analysis and on the other hand he was an inspired defender of the here-developed view (see the much quoted passage of 'A Plea for Excuses', in his Philosophical Papers, p. 232).

${ }^{15}$ W.v.O. Quine, Word and Object, p. 270 ss. See also my The Philosophical Inquiry, pp. $15 \mathrm{ff}$.

${ }^{16}$ W.v.O. Quine: Word and Object, pp. 271-272. 
thing else, except for reasons of semantic accent. A theoretical physicist and a philosopher of mind, for example, can be seen as analyzing and combining concepts as much as dealing with empirical questions. Hence, all that we can intend by saying that philosophy is conceptual analysis is to point to some methodological resources, and not to an indispensable approach, and still less to its proper subject matter.

To the question of whether all philosophy might be an anticipation of science, assuming the concept of science that we have suggested, the only answer is that we have no reason to think otherwise. In fact, the only chance we have to make real progress is by holding this view as a normative assumption. ${ }^{17}$

\section{The more complete framework}

While I have limited myself here, for methodological reasons, to the relationship between philosophy and science, I believe that this is only one aspect of the more complete framework that places philosophy within a broader perspective. In my book on the nature of philosophy. ${ }^{18}$ I attempted to achieve this broader perspective conceiving traditional philosophy as a derivative cultural activity that can be seen as an amalgam of three other cultural activities: art, religion, and science. These activities could be represented as forming the edges of a triangle inside of which different philosophical activities can be placed. The scientific edge of the triangle is success and truth-oriented, the mystical-religious edge is responsible for the transcendental element, and the characteristic breadth of the philosophical quest, the aesthetic-artistic edge, is responsible for the metaphorical aspects of the philosophical discourse. Inside the triangle, in its centre, can be found philosophies that have in

${ }^{17}$ There are many further problems that cannot be touched on here. For example, how to include certain non-central domains, like those of the philosophy of existence, philosophy of life, or critique of culture - which have changeable subjects - in our schema? (Probably in ways similar to those in which the historical sciences can be consensualizable). Another point is that the development of science can itself create a space for new and previously unexpected philosophical fields. The philosophy of computational science is an example.

${ }^{18}$ C.F. Costa: The Philosophical Inquiry: Towards a Global Account. 
sufficient measure artistic (metaphorical), religious (transcendental) and scientific (truth-oriented) aspects (examples are Platon's Republic, Descartes' Meditations, Wittgenstein's Tractatus). However, there are forms of philosophy that are located near the artistic edge (like Nietzsche's Zaratustra and Novalis' Hymns to the Night), near to the mystical-religious edge (like John Scott's The Divisions of Nature and Meister Eckhart's Sermones, near to the scientific edge (like Searle's Speech Acts and Carnap's Logical Grammar of Language). There are even cultural traditions linking philosophy with an edge, like the French literature oriented tradition, the German mystically oriented tradition and the English scientifically oriented tradition. And it is possible to perceive in the sub-domains a broad slow movement from the artistic-mystical side of the triangle to the scientific edge as an inevitable consequence of the speeding progress of science.

Cláudio F. Costa

Federal University of Rio Grande do Norte

\section{References}

Austin, J.L. A Plea for Excuses. In Philosophical Papers. Oxford: Oxford University Press, 1961.

Ayer, A.J. Wittgenstein. New York: Pelican Books, 1985.

Brandom, R., Barry Stroud, Allen Wood and Karl-Otto Apel. In What is Philosophy? ed. by C.P. Ragland \& S. Reidt. Yale: Yale University Press, 2001.

Comte, A. Cours de Philosophie Positive. In Ouvres. Paris: 1968 (1830-1842), vol. 1.

Costa, C.F. 2002. The Philosophical Inquiry: Towards a Global Account. Langham: UPA.

Dummett, M. Can Analytic Philosophy be Systematic and Ought to Be? In Truth and Other Enigmas. London: Duckworth, 1978.

Guthrie, W.K.C. A History of Greek Philosophy. Vol. 1. Cambridge: Cambridge University Press, 1962.

Habermas, J. Wahrheitstheorien. In Vorstudien und Ergänzungen zur Theorie des Kommunikativen Handelns. Frankfurt: Suhrkamp, 1984.

Kenny, A. Aquinas on Mind. London: Routledge, 1993.

Longino, H.L. The Fate of Knowledge. Princeton: Princeton University Press, 2002.

Odell (eds.) The Owl of Minerva. New York: Harvester Press, 1975.

Popper, K.R. Back to the Pre-Socratics. In Conjectures and Refutations. London: Routledge, 1962.

Quine, W.v.O. A Letter to Mr. Osterman. In The Owl of Minerva, ed. by C.J. Bontempo \& S.J. Odell. New York: Free Press, 1975.

Quine, W.v.O. Word and Object. Cambridge: MIT-Press, 1960.

Russell, B. My Philosophical Development. London: Routledge, 2004.

Strawson, P.F. Analysis, Science and Metaphysics. In Linguistic Turn: Recent Essays in Philosophical Method, ed. by R. Rorthy. Chicago: Chicago University Press, 
1967.

Tugendhat, E. Überlegungen über die Methode der Philosophie aus Analytischer Sicht. In Philosophische Aufsätze. Frankfurt: Suhrkamp, 1992.

Wittgenstein, L. Philosophische Untersuchungen. Frankfurt: Suhrkamp, 1986.

Wood, A. postscript of B. Russell's My Philosophical Development. London: George Allen \& Unwin, 1975.

Ziman, J.M. Public Knowledge: an Essay Concerning the Social Dimension of Science. New York: Cambridge University Press 1968).

Ziman, J.M. Real Science. Cambridge: Cambridge University Press, 2000. 